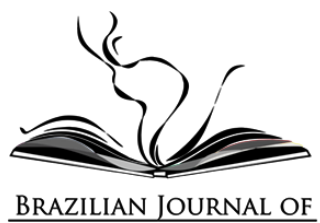

\title{
LA PARTICIPACIÓN DE LAS ORGANIZACIONES DE PROFESORES EN LOS PROCESOS DE REFORMA EDUCATIVA EN AMÉRICA LATINA (1990-2010)'
}

\author{
A PARTICIPAÇÃO DAS ORGANIZAÇÕES DE PROFESSORES NOS \\ PROCESSOS DE REFORMA EDUCACIONAL NA AMÉRICA LATINA
} (1990-2010)

THE PARTICIPATION OF TEACHERS' ORGANIZATIONS IN THE EDUCATIONAL REFORM PROCESSES IN LATIN AMERICA (1990-2010)

\author{
José Humberto Trejo Catalán ${ }^{2}$ (iD \\ Centro Regional de Formación Docente e Investigación Educativa, México
}

\begin{abstract}
Resumen: El presente trabajo se interroga sobre la influencia de las organizaciones de profesores en el desarrollo de las reformas educativas en Argentina, Brasil, Chile y México; países que comparten las similitudes propias de la matriz socioeconómica y cultural de América Latina; asimismo, el análisis ubica estos procesos en el marco de la apertura democrática que vivió la región desde los años ochenta del siglo pasado hasta su consolidación, en la primera década del siglo XXI. Para lograr explicar los posicionamientos y estrategias de acción política de las organizaciones de profesores frente a las reformas educativas, se recurrió a una metodología cualitativa, apoyada en los siguientes métodos y enfoques: la teoría general de sistemas, el enfoque de políticas públicas y los estudios comparados en ciencias sociales. Finalmente, como técnica se recurrió al análisis documental, mismo que se apoyó en el uso de datos y razonamientos causales. Como consecuencia, en el presente trabajo se logró identificar una estrecha relación entre los procesos de democratización política y reforma educativa, como determinantes de distintas rutas para la profesionalización del magisterio a partir de las estrategias de acción de este gremio, cuyo peso político se potenció notablemente durante el periodo analizado.
\end{abstract}

\footnotetext{
${ }^{1}$ El presente artículo tiene como antecedente los resultados de una investigación previa desarrollada por la misma autor, señalada en las referencias.

${ }^{2}$ Doctor en Ciencias Políticas y Sociales. Centro Regional de Formación Docente e Investigación Educativa.

E-mail: humberto.trejo@cresur.edu.mx
} 
Palabras clave: Transición Democrática, Reforma Educativa, Organizaciones de Profesores, Sistemas Educativos Nacionales, Políticas de Profesionalización del Magisterio.

Resumo: Este trabalho questiona a influência das organizações de professores no desenvolvimento de reformas educacionais na Argentina, Brasil, Chile e México; países que compartilham as semelhanças da matriz socioeconômica e cultural da América Latina. A análise também coloca esses processos no quadro da abertura democrática que a região experimentou desde os anos oitenta do século passado até sua consolidação, na primeira década do século XXI. Para explicar as posições e estratégias de atuação política das organizações de professores em face das reformas educacionais, utilizou-se uma metodologia qualitativa, apoiada pelos seguintes métodos e abordagens: teoria dos sistemas gerais, abordagem de políticas públicas e estudos comparativos em ciências sociais. Por fim, como técnica, utilizou-se a análise documental, que se baseou no uso de dados e de raciocínios causais. Como resultado, o presente trabalho foi capaz de identificar uma estreita relação entre os processos de democratização política e reforma educacional, como determinantes de diferentes rotas para a profissionalização do magistério com base nas estratégias de ação dessa guilda, cujo peso político foi muito fortalecido durante o período analisado.

Palavras-chave: Transição Democrática, Reforma Educacional, Organizações de Professores, Sistemas Nacionais de Educação, Políticas de Profissionalização do Magistério.

Abstract: This paper questions the influence of teachers' organizations in the development of educational reforms in Argentina, Brazil, Chile and Mexico; countries that share the similarities of the socioeconomic and cultural matrix of Latin America; likewise the analysis places these processes within the framework of the democratic opening that the region lived from the eighties of the last century until its consolidation, in the first decade of the 21st century. In order to explain the positions and strategies of political action of teachers' organizations towards educational reforms, a qualitative methodology was used, supported by the following methods and approaches: the general theory of systems, the approach of public policies and comparative studies in social sciences. Finally, as a technique, documentary analysis was used, which was based on the use of data and causal reasoning. Throughout the work it is possible to identify a close relationship between the processes of political democratization and educational reform, as determinants of different routes for the professionalization of the teaching profession based on the action strategies of this guild, whose political weight was significantly enhanced during the analyzed period.

Keywords: Democratic Opening, Teachers' Organizations, National Educational Systems, Educational Reform, Teacher Training Policies. 


\section{INTRODUCCIÓN}

Entre la última década del siglo pasado y la primera del presente, el magisterio organizado (entendiendo por éste al profesorado de educación básica o fundamental) tuvo una intensa participación en los procesos de transición o restauración democrática, así como en las reformas educativas que se desarrollaron en América Latina.

Nunca como entonces la naturaleza del gremio magisterial como generador y gestor de significados y narrativas tuvo una influencia mayor en el espacio de las disputas políticas. Ideas como la siguiente, cobraron gran fuerza entre el magisterio:

[...] los educadores necesitan las escuelas como esferas públicas donde la dinámica del compromiso popular y la política democrática puedan cultivarse como parte de la lucha por un Estado democrático radical. (GIROUX, 1997, p. 225).

De igual forma, el peso de los colectivos magisteriales como ciudadanos con un alto grado de organización política, cohesionados por tradiciones e intereses gremiales comunes, con presencia territorial amplia -incluso en las localidades más dispersas-y con liderazgo social representó un capital de primer orden para los partidos políticos que, a partir de los noventa, se disputaban el poder en un contexto democrático,

[marcado por] una ampliación, diversificación e intensificación de la conflictividad social y política [...] [donde] la mayor parte de los enfrentamientos tuvieron como protagonista principal al sector asalariado (público y privado) sindicalizado y, en particular, al magisterio. [Cuya prioridad en la negociación con el Estado se relacionó] [...] casi exclusivamente con las condiciones salariales y laborales de maestros y profesores, el presupuesto para la educación [...] y, en última instancia, la capacitación y el perfeccionamiento profesional." (GENTILI, et al., 2004, pp. 1252-1254). 
Sin embargo la movilización del magisterio buscó trascender los límites de la educación y los sistemas educativos nacionales. En todo caso, se ubicó en el plano de la "función política" propia de las "retóricas educativas" asumidas en distintos momentos por el magisterio latinoamericano para i) "unir" intereses distintos, ii) "movilizar" grupos "a través de fines y justificaciones especiales", y iii) "legitimar" acciones, decisiones o demandas, "[...] construyendo una imagen [...] aceptable para el resto de la comunidad [...]" (RATINOFF, 1994, p. 24).

Con base en lo anterior, la relevancia de esta función política de las organizaciones de profesores en el proceso de transición democrática no pudo haber sido más importante; a fin de cuentas, el ejercicio democrático supone fundamentalmente una ampliación de derechos, en la media que requiere:

[...] el ejercicio de la racionalidad comunicativa, la existencia de condiciones sociales en sociedades modernas, pluralistas y complejas; un sistema electoral institucionalizado que garantice procesos electorales limpios; la libertad de asociación, movimiento y disponibilidad de información no monopolizada, la existencia de una ciudadanía con derechos y obligaciones; y un régimen jurídico imparcial que garantice el ejercicio de derechos civiles y políticos. (ZAMORA, 2016, p. 165).

En este contexto, la educación es un factor que hace posible el ejercicio de múltiples derechos, como los políticos, los electorales, entre otros. De manera que el protagonismo del magisterio en los procesos regionales de transición política entre los años noventa y la primera década del siglo XXI fue relevante:

- Por su función política, anclada fundamentalmente a una retórica nacionalista que apelaba a los valores propios de las comunidades políticas imaginadas (ANDERSON, 1993) que dieron origen, unidad y sentido de futuro a los Estados Nacionales de América Latina;

- Por su capacidad de organización y movilización política, que hizo de las organizaciones gremiales del magisterio, aliados estratégicos fundamentales de los principales partidos políticos de los países analizados; y, 
- Por la función pedagógica o propiamente educativa, que es su materia y se proyectaba en la necesidad de acompañar y soportar los procesos transicionales en didácticas sociales capaces de propiciar la participación social en la democracia, de promover y enseñar el ejercicio de nuevos derechos, de instalar nuevas prácticas y valores sociales y culturales -acordes con los principios democráticos-, y de proyectar desde el espacio de la Reforma Política de los Estados, las Reformas Educativas y de la profesión y profesionalidad docente necesarias para poner al día los procesos educativos y docentes con la convivencia democrática, la globalización y la sociedad del conocimiento, por resumir en una frase el cúmulo de transformaciones y desafíos que enfrentó el mundo en el periodo de este análisis.

La primera década del siglo XXI marcó cambios notables en la dinámica de la participación política del magisterio. Como veremos más adelante, las organizaciones de profesores más representativas de los países analizados se vinculan claramente con partidos o coaliciones políticas que ejercieron el gobierno, lo que les redituó avances en algunas demandas como: i) la participación en el diseño de políticas y programas educativos, en algunos casos, incluso la proyección de sus miembros o personajes afines como directivos; ii) mejores condiciones laborales -salarios, incentivos al desempeño, seguridad en el empleo-; y, iii) la ampliación de las oportunidades de desarrollo profesional a través de acceso a programas de formación continua y trayectorias de desarrollo profesional, también conocidas como carreras docentes (PROGRAMA DE PROMOCIÓN DE LA REFORMA EDUCATIVA DE AMÉRICA LATINA Y EL CARIBE, 2004).

Sin embargo, la cercanía con los gobiernos nacionales y, en algunos casos, el ejercicio de la política educativa a través de personajes claramente vinculados al magisterio, cobró la factura en la medida que dichos gobiernos se fueron desgastando. Tanto los partidos y coaliciones políticas originalmente opuestas a los movimientos respaldados por los grupos 
mayoritarios del magisterio en sus respectivos países, como los adversarios internos que no coincidían con las posiciones hegemónicas del magisterio, emergieron en la medida que los gobiernos o coaliciones de gobierno en las que participaban se fueron desgastando.

En todo caso, el presente trabajo contextualiza el desarrollo de la profesión docente como resultado de las tensiones y logros de sus organizaciones gremiales (entre 1990 y 2010), en tanto actores de los procesos que redefinieron las relaciones económicas, sociales, culturales y, desde luego, políticas de sus respectivos países.

De hecho, la participación de las organizaciones de profesores en la formulación de políticas para la profesionalización magisterial ha sido muy activa en la región, como se muestra en el caso de los países analizados: Argentina, Brasil, Chile y México, particularmente en el periodo que nos ocupa.

Desde la perspectiva del análisis gubernamental y la gestión pública, la década de los noventa se define por un cambio de modelo de desarrollo hacia las llamadas reformas neoliberales, al respecto cabe señalar que:

El sistema educativo es parte integrante de las sociedades
nacionales en las cuales se realizan transformaciones profundas en
sus modos de integración a la globalización en sus formas de
producción debido al tránsito de la economía basada en el
conocimiento. Es parte también de la estructura social, del sistema
político y de los sistemas culturales. (JIMÉNEZ, 2007, p. 101)

Frente a la quiebra de los modelos desarrollistas -y la salida de los gobiernos autoritarios en Brasil, 1985-1988; Argentina, 1983-1989; Chile, 1990 y México, 1994-2000- "[...] las nuevas reglas eran las del mercado y nuestros países estaban obligados a mejorar la estructura de competencias de sus recursos humanos para no quedar al margen del desarrollo." (CONCHA, 2005).

Por ello, la reforma de la educación se ubicó como un tema relevante en las agendas para la reforma del Estado. En ambas, las organizaciones de profesores tenían intereses fundamentales en la medida que potenciaron su participación: i) como profesionales de la educación interesados en 
tener voz en la revisión de su materia de trabajo ¿cómo?, ¿con qué? y ¿para qué educar? ; ii) como trabajadores del Estado, sensibles a los procesos de ajuste definidos por las políticas orientadas a la reducción de presupuestos y el incremento de responsabilidades; iii) como profesionales de la educación con responsabilidad en la gobernanza de los sistemas educativos y de gestionar el cambio -pedagógico, de gestión y de sentidoen dichos sistemas (TEDESCO, 2007, p. 91).

\section{EL GIRO DEMOCRÁTICO Y LA TRANSICIÓN EDUCATIVA}

El giro democrático de los años noventa impactó a las estructuras estatales, transitando del sentido de gobernar con referencia únicamente a la gobernabilidad, en la que el Estado toma decisiones de carácter unilateral y unidireccional (AGUILAR, 2006), a otro apegado al enfoque de la gobernanza o la Nueva Gestión Pública sustentada en los principios gerenciales para el desempeño de los Estados y sus instituciones con base en: la eficiencia, la eficacia, la calidad, la asignación de presupuesto por resultados, el rol del Estado como coordinador, la reformulación del vínculo con nuevos actores, la participación, la corresponsabilidad y la rendición de cuentas. En este contexto, las reformas educativas fueron construidas bajo una lógica más abierta y participativa, como políticas públicas, y ya no como meras decisiones o programas de gobierno.

Las reformas educativas de los noventa, enmarcadas en lo que Ratinoff (1994, p. 36) define como la Retórica del Capital Humano, "[...] que permitía redefinir el producto educativo válido para la sociedad como el resultado de una operación exclusivamente utilitaria", compartieron medidas como: i) la descentralización; ii) el incremento de la participación social en la educación de actores diversos y no sólo el magisterio; iii) la extensión de los ciclos de educación obligatoria; iv) la profesionalización docente y el desarrollo de reglas para su ingreso y promoción; v) la construcción de sistemas de incentivos, vi) la gestión escolar; vii) el desarrollo de sistemas de información educativa; viii) la evaluación de los 
resultados de los sistemas educativos; y ix) la búsqueda de la equidad educativa (LOYO, 2018; VÁZQUEZ, 2015).

Las distintas formas en que cada una de estas estrategias y acciones se concretaron en los países analizados -cuya revisión excede los propósitos de este trabajo- terminaron configurando los actuales sistemas educativos que enfrentan la contradicción de haber cambiado en múltiples aspectos (planes y programas de estudio; estructura, organización y funcionamiento; la docencia y la profesionalización del magisterio); pero no así en sus resultados agregados, que básicamente continúan siendo insatisfactorios y por debajo de las condiciones esperables para la región. De acuerdo a su grado de desarrollo:

Los países de América Latina y el Caribe presentan consistentemente un desempeño deficiente en las evaluaciones internacionales [de aprendizajes]: aún después de controlar por la variable del PIB per cápita, los estudiantes de la región se desempeñan bastante por debajo de aquellos de los países de la OCDE y de Asia oriental (VEGAS; PETROW, 2008, p. 21)

Cabe especular si nuestros sistemas educativos se quedaron atrapados en un proceso de cambio institucional que no se propuso -o no logró- alterar las bases de una organización económica que genera desigualdad social. En este sentido, las reformas educativas de los noventa se mantuvieron en un plano pedagógico, técnico o superestructural, a pesar de que plantearon "[...] acciones que comprometían a toda la sociedad [...] y propusieron procesos y metas de mediano y largo plazo." (CONCHA, 2005).

De esta manera, el giro democrático en la educación se correspondió con un giro pedagógico que cambió la organización y el funcionamiento de los sistemas educativos nacionales; como la identidad de las y los docentes, sus formas de organización y la dinámica de sus sindicatos. 


\section{LAS REFORMAS EDUCATIVAS Y PROFESIONALIZACIÓN DOCENTE}

Las reformas promovidas en los años noventa buscaron concebirse como reformas de la enseñanza, para lo cual desarrollaron sistemas de profesionalización docente (LOYO, 2001; VIEIRA, 2008) capaces de atender al menos los siguientes aspectos: la construcción de sistemas de evaluación, el desarrollo de estímulos al desempeño profesional, el incremento de la flexibilidad en el trabajo docente, el aumento del compromiso con los procesos de actualización, entre otros.

En suma, la profesionalización docente -uno de los ejes fundamentales de las reformas educativas de la década de los noventaimplicó "[...] estructurar la formación profesional bajo los parámetros de la acreditación y la certificación de los programas y de una revisión a fondo de los estatutos docentes." (VÁZQUEZ, 2015, p. 100); asimismo sumó al perfil docente un conjunto de valores, prácticas y nuevas actitudes hasta generar lo que algunos autores llaman profesionalidad docente, es decir, el conjunto de competencias específicas de su hacer (OLIVEIRA, 2013).

De manera que diseñar y desarrollar políticas para fortalecer la profesionalización docente pasó a ser una prioridad en los procesos de reforma. El desafío de profesionalizar al magisterio implicó modificar estructuras e instituciones profundamente arraigadas en nuestros países, bajo un enfoque integral de los siguientes aspectos básicos "[...] la formación, las condiciones de trabajo y de carrera y el sistema recompensas materiales y simbólicas que se ofrecen." (TEDESCO; TENTI, 2002, p. 21). En este sentido, la disyuntiva no fue reformar o no reformar los sistemas educativos, sino hacerlo con los maestros o a pesar de ellos.

No obstante, las reformas emprendidas no lograron en su momento -y aún hoy tienen como tarea pendiente: i) mejorar la eficacia social de la educación; ii) hacer efectivo el derecho a una educación de igual calidad; iii) impactar los procesos de enseñanza-aprendizaje que tienen lugar en las salas de clases y en las escuelas (RATINOFF, 1994; TEDESCO, 2007; BLANCO, 2014). 


\section{ORGANIZACIONES DE PROFESORES EN LOS PAÍSES COMPARADOS: NOTAS METODOLÓGICAS}

Para lograr explicar los posicionamientos y estrategias de acción política de las organizaciones de profesores frente a las reformas educativas se recurre a una metodología cualitativa, apoyada en los siguientes métodos y enfoques: la teoría general de sistemas, el enfoque de políticas públicas y los estudios comparados en ciencias sociales. Finalmente, la técnica de revisión es de carácter documental, con apoyo en el uso de datos y razonamientos causales.

Desde la teoría general de sistemas, las organizaciones de profesores se reconocen como entidades (o subsistemas) influidas e interactuantes con otros sistemas como el Estado, macrosistema del que forma parte, y microsistemas (estados o departamentos, los municipios, las zonas escolares, las escuelas, las aulas y los docentes).

Es decir, desde ésta teoría, el estudio de los fenómenos sociales tiene sentido en función del contexto o sistema del que son parte y en función de la interacción dinámica de dichas partes (BERTALANFFY, 1989). Desde este enfoque "[...] lo importante son las relaciones y los conjuntos que a partir de ellas emergen." (ARNOLD; OSORIO, 1998, p.1). Estas interrelaciones se presentan en los sistemas educativos nacionales, los sistemas políticos nacionales y los sistemas de profesionalización docente.

De acuerdo a lo anterior puede afirmarse que los cambios en los sistemas educativos nacionales derivan de tensiones externas e internas de diverso tipo y, eventualmente, dan lugar a nuevos arreglos sobre el entendimiento del ser, el deber ser, el cómo y el para qué de la educación y sus actores (TREJO, 2015).

Enfoque de políticas públicas estudia los procesos de definición de los objetivos públicos del Estado, el desarrollo de organizaciones y programas dirigidos a alcanzar dichos objetivos y el impacto de esos 
programas (MÉNDEZ, 1993). En suma, busca resolver problemas que afectan el interés público o la dignidad de las personas (PARSONS, 2007).

En consonancia con la teoría general de sistemas, desde el enfoque de las políticas públicas se puede analizar los resultados de tensiones externas e internas de diverso tipo antes mencionadas en los sistemas educativos nacionales, los sistemas políticos nacionales y los sistemas de profesionalización docente, como producto de un proceso de decisiones (en este sentido, no es neutral) y el diseño de las estrategias orientadas a la resolución dichas tensiones; y dentro de este marco dar sentido a los intercambios entre los actores.

A decir de Sartori (1984), la comparación es un ejercicio indispensable para la comprensión y el desarrollo del enfoque de las políticas públicas, en la medida que permite identificar variables que explican la mecánica (causalidad) de los procesos a estudiar entre procesos que ocurren en un mismo periodo pero en ámbitos diferentes (sincronismo histórico). De manera que los parámetros que utiliza el método comparativo pueden y suelen ser diversos, en razón de los fenómenos sociales que se pretenda analizar:

El método comparativo describe similitudes y disimilitudes, trabaja con el presente siendo su despliegue horizontal, compara objetos que pertenecen al mismo género, se basa en el criterio de homogeneidad y por ende se diferencia de la mera comparación. (TONON, 2011, p. 11).

Dicho análisis permitirá sostener o desechar la hipótesis de trabajo que consiste en argumentar que la influencia de las organizaciones de profesores representa una variable significativa para explicar el diseño, la gestión y el impacto de las reformas educativas, a través de los sistemas de profesionalización docente y las políticas de profesionalización del magisterio. En este sentido, fue necesario identificar y explicar los alcances de elementos comunes a los países comparados, tanto en su desarrollo político, como en los procesos de reforma educativa a partir del último cuarto del siglo XX y la primera década del XXI. 
Para ello, se seleccionaron a cuatro países de América Latina: Argentina, Brasil, Chile y México donde -además de compartir las similitudes propias de la matriz socioeconómica y cultural de América Latina-, los tres primeros: i) conforman los Estados más grandes de Latinoamérica por su territorio, población y el tamaño de sus economías; ii) son Estados Federales; iii) representan centros económicos y políticos subregionales y, junto a Chile, experimentaron procesos de transición democrática y reformas educativas durante la etapa de análisis. Finalmente, de cada uno de ellos se retomó a las organizaciones de profesores con mayor membresía relativa (LOYO, 2001):

- Argentina, Confederación de los Trabajadores de la Educación de la República de Argentina (CTERA), 37.7\%.

- Brasil, Confederação Nacional dos Trabalhadores em Educação (CNTE), 33.8\%.

- Chile, Colegio de Profesores de Chile A.G., 75.5\%.

- México, Sindicato Nacional de Trabajadores de la Educación (SNTE), $97.8 \%$.

\section{ORGANIZACIONES DOCENTES, REFORMAS EDUCATIVAS Y POLÍTICAS DE PROFESIONALIZACIÓN DEL MAGISTERIO}

\subsection{ARGENTINA}

En el caso que nos ocupa, durante la década de los cincuenta, se "[...] condensa un conjunto de transformaciones de envergadura, ya que se dieron en ese tiempo cambios que podríamos calificar como "estructurales" en la relación entre Estado y docencia." (GUTIÉRREZ, 2014, p. 16). Estos cambios derivaron en la promulgación, en 1954, de un Estatuto Docente, bajo la iniciativa del presidente Perón (1946-1955), lo que signó un 
compromiso de largo aliento entre buena parte del magisterio y el justicialismo argentino, en la medida que dicho Estatuto:

[...] responde a legítimas y viejas aspiraciones de ese esforzado gremio, regla desde ya las actividades del mismo y confiere a sus integrantes la jerarquía moral y los recursos pecuniarios dignos que corresponden a sus condiciones de forjadores de la juventud de la Patria, que tendrá en el futuro la responsabilidad de reafirmar los principios de soberanía política, independencia económica y justicia social, que ha plasmado con su genio tutelar el Presidente de la Nación, General Juan Perón, para el bienestar de las generaciones presentes y futuras (Estatuto del Docente Argentino del General Perón, 1954).

Posteriormente, en 1973 -y nuevamente bajo el cobijo del peronismo (1973-1974) - se creó la Confederación de Trabajadores de la Educación de la República de Argentina (CTERA), que conjuntó cerca de 140 sindicatos provinciales. La nueva organización, al constituirse como federación, no quedó subordinada a ninguna otra organización gremial y surgió con una clara autonomía frente al Estado.

La Junta Militar que gobernó al país entre 1976 y 1983, marcó un distanciamiento entre el magisterio y el gobierno que se prolongará más allá de la dictadura. En este contexto, la CTERA se opuso a la descentralización de los servicios educativos (1992); la negociación entre sindicatos y gobierno resultaba la única vía transitable hacia una reforma educativa, que pudiera tener un alcance de fondo para el país en lo financiero, administrativo, político y educativo. A partir de este objetivo, la CTERA logró participar en la definición de políticas curriculares y evaluación; de capacitación y actualización docente; y de profesionalización e incentivos, que formaron parte de la Ley Federal de Educación de 1993.

A pesar de los acuerdos logrados, la CTERA, "[...] mantuvo un discurso de oposición a la reforma educativa... [acusándola] de construir un proceso de 'desresponsabilización' del estado nacional en materia educativa, lo que se apoyaba en el retiro total de la gestión de las escuelas." (PERAZZA; LEGARRALDE, 2008, p. 31). Lo cual no era exacto ya que el Gobierno Federal recentralizó en los hechos facultades importantes como la regulación del currículum, la evaluación, la capacitación docente, 
las políticas compensatorias y el financiamiento internacional, como ya se había señalado.

Con la vuelta del peronismo en 2003 se registró una suerte de reconciliación entre los principales sindicatos docentes y el gobierno federal. Se aprobaron un conjunto de leyes -impulsadas por el gobierno federal y consensuadas con las organizaciones de profesores - que transformaron la condición del magisterio en el sistema educativo nacional y sentaron las bases para avanzar en una profunda transformación del sistema y el modelo educativo: i) La Ley de Educación Técnico Profesional; ii) La Ley de Financiamiento Educativo; y iii) La Ley Nacional de Educación.

Por lo anterior, cabe decir que el principal propósito de la CTERA durante el periodo de análisis fue la reivindicación de los derechos laborales de los docentes, cancelados durante el régimen militar, como también recuperar su capacidad de movilización e influencia política.

Cabe señalar que desde 1958, Argentina cuenta con un Estatuto Docente. Es notable el papel asignado a "las juntas de calificación" que forman y resguardan los expedientes laborales de los maestros y se integran entre la representación "oficial" (el patrón) y una representación de los propios docentes (TREJO, 2015).

\subsection{BRASIL}

En 1960 -en el contexto del populismo- 26 delegaciones docentes crearon la "Confederação dos Professores Primários do Brasil" (CPPB) -que en 1979 pasaría a ser la "Confederação dos Professores do Brasil" (CPB), ampliando su perfil a todo tipo de profesores-; sin embargo, el golpe militar de 1964 obligó a la CPPB a continuar sus actividades con un bajo perfil, no obstante $-\mathrm{y}$ a pesar de su relativa clandestinidad durante los setentas- la CPPB, después CPB, continuó creciendo hasta posicionarse como el principal interlocutor de la negociación gremial del magisterio. 
En 1980 la principal organización del magisterio brasileño -"Confederação dos Professores do Brasil" (CPB), antes "Confederação dos Professores Primários do Brasil" (CPPB) creada en 1960- buscó incidir en la política de Estado participando en la creación del Partido dos Trabalhadores (PT). Esto sucedía en plena dictadura militar (1964-1985), con el propósito de defender los derechos laborales de un magisterio atomizado y empobrecido por la debilidad de los municipios y la mayoría de los estados para gestionar sus sistemas educativos.

La CPB organizó foros en 1984 y 1985 para diagnosticar el estado de la educación en el país, develando las condiciones precarias en las que se desarrollaba. En 1990, en el marco del "Forum", se integraría la "Confederação Nacional dos Trabalhadores em Educação" (CNTE). Esta unificación estableció como principal objetivo la obtención de un piso salarial; demanda que obtuvo respaldo a través de la promulgación de la Lei No 9.424 que reglamenta al Fundo de Manutenção e Desenvolvimento do Ensino Fundamental e de Valorização do Magistério (FUNDEF) y la promulgación de la Lei de Diretrizes e Bases da Educação Nacional (LDB) en 1996, también Ilamada, Lei Nº 9.394

En Brasil, la Lei $N^{\circ}$ 4.881-A funge como el único Estatuto Docente aplicable en todo el país para la educación superior, pero no para el magisterio de educación básica; sin embargo, la LDB antes mencionada, estableció un marco atendible en toda la federación que determinó una ruta a la vez relevante y sencilla para la profesionalización del magisterio:

Art. 67.Os sistemas de ensino promoverão a valorização dos profissionais da educação, assegurando-lhes, inclusive nos termos dos estatutos e dos planos de carreira do magistério público: I ingresso exclusivamente por concurso público de provas e títulos; II - aperfeiçoamento profissional continuado, inclusive com licenciamento periódico remunerado para esse fim; III - piso salarial profissional; IV - progressão funcional baseada na titulação ou habilitação, e na avaliação do desempenho; $\vee$ - período reservado a estudos, planejamento e avaliação, incluído na carga de trabalho; VI - condições adequadas de trabalho. Parágrafo único. A experiência docente é pré-requisito para o exercício profissional de quaisquer 
outras funções de magistério, nos termos das normas de cada sistema de ensino. (Lei No 9.394, 1996).

Junto con ello, la creación y consolidación del FUNDEF, en 1996, que apalancó el financiamiento de la progresión salarial de las y los maestros, fueron medidas determinantes para transformar el sistema educativo brasileño.

\subsection{CHILE}

Chile ha sido presentado como el modelo más aventajado -y en muchos aspectos exitoso- de la propuesta neoliberal. Esto se refleja también en el prolijo y complejo entramado de reformas educativas y magisteriales que se registran en el periodo, el cual fue posible, en un primer momento, por la ausencia de contrapesos frente a las decisiones gubernamentales $\mathrm{y}$, posteriormente, como resultado de los ajustes demandados por distintos sectores educativos y sociales frente a estas decisiones unilaterales.

En 1974 la Junta Militar disolvió el sindicato magisterial y creó el Colegio de Profesores de Chile A.G. La adscripción de los docentes fue obligatoria. En 1978, se decretó la Ley de Carrera Docente y en 1990, antes de concluir su periodo, Pinochet aprobó la Ley Orgánica Constitucional de la Enseñanza (LOCE).

Tras la dictadura de Augusto Pinochet (1973-1990), el Colegio de Profesores recuperó un papel relevante en la negociación de las reformas educacionales impulsadas por los gobiernos de la Concertación de

\footnotetext{
${ }^{3}$ Art. 67. Los sistemas educativos promoverán la valorización de los profesionales de la educación, asegurándoles, incluso de conformidad con los estatutos y planes de carrera del magisterio público: I - entrada exclusivamente por concurso público de pruebas y títulos; II - mejora profesional continua, incluida la licencia periódica pagada para este fin; III - piso salarial profesional; IV - progresión funcional basada en la valoración o calificación, y la evaluación del desempeño; $\vee$ - período reservado para estudios, planificación y evaluación, incluido en la carga de trabajo; VI - condiciones de trabajo adecuadas. [ Y considerar que] (...) La experiencia docente es un requisito previo para el desempeño profesional de cualquier otra función docente, de acuerdo con las normas de cada sistema educativo. (Traducción del autor). (Lei N 9.394, 1996).
} 
Partidos por la Democracia (1990-2010) ${ }^{4}$. En este sentido, "Una de las primeras medidas fue la promulgación en 1991 de un Estatuto Docente." (BISCARRA; GIACONI; ASSAÉL, 2015, p. 87).

Derivado del contexto en que surgió, la LOCE -justo en el cierre de la Dictadura- en el periodo de Concertación se consideró indispensable modificarla. Para ello, en 1994 y por común acuerdo entre el gobierno y organizaciones docentes, se instauró la Comisión Nacional para la Modernización de la Educación, cuyos temas prioritarios fueron: actualizaciones curriculares, la revalorización del rol de la familia, la atención a los grupos vulnerables, la revisión de los resultados del Sistema de Medición de la Calidad de la Educación, el modelo pedagógico, la formación docente, la autonomía profesional, los salarios a docentes, el financiamiento de la educación, la subvención, la infraestructura, las jornadas laborales, y, finalmente, el rol del Estado (HERNÁNDEZ; MELLADO; MUÑOZ, 2015).

En este proceso, las políticas de profesionalización docente han estado sujetas a un marco normativo compuesto por: la creación de Sistema Nacional de Evaluación del Desempeño de los Establecimientos Educacionales Subvencionados en 1995, la ley que crea la Jornada Escolar Completa de 1997, la Ley 19.715 a través de la cual se crea la Asignación de Excelencia Pedagógica, la Red de Maestros en 2001, la Ley Sobre Evaluación Docente en 2004, la Ley de Subvención Escolar Preferencial en 2008, la Ley General de Educación en 2009 y, finalmente, en 2011, la Ley de Calidad y Equidad de la Educación que establece modificaciones al Estatuto Docente.

Entrado el siglo XXI, el discurso meritocrático y la estructura del sistema educativo bajo esos mismo principios, generó tal presión en la sociedad que los estudiantes de secundaria primero, y otros actores (universitarios, investigadores, docentes, padres de familia) después se movilizaron bajo la consigna de democratizar la calidad educativa, ponerla

\footnotetext{
${ }^{4}$ Esta coalición de partidos de centro y centro-izquierda alcanzó y mantuvo la presidencia con Patricio Aylwin (1990-1994), Eduardo Frei (1994-2000), Ricardo Lagos (2000-2006) y Michelle Bachelet (2006-2010), quien tuvo un segundo periodo presidencia (1914-1918), pero ya no en el marco de la Concertación.
} 
al alcance de todos, incluso y sobre todo en los planteles que atienden a la población con menores recursos, dada la segregación social que generó el modelo chileno, que alentó la privación de la educación pública en todos los niveles educativos.

\subsection{MÉXICO}

Lo que caracteriza al Sindicato Nacional de Trabajadores de la Educación (SNTE) -fundado en 1943- es su membresía monopólica, al concentrar al $97.8 \%$ de los docentes del país ${ }^{5}$. En este sentido, el SNTE es un interlocutor relevante en las decisiones políticas en el ámbito de la educación básica y normal (GINDIN, 2008). Asimismo, desde su fundación, éste ha gozado de una estrecha relación con los gobiernos en turno (VÁZQUEZ, 2015).

Como resultado de este proceso se abrió una línea de negociación entre la Secretaría de Educación Pública (SEP) y el SNTE que cuenta con cuatro momentos particularmente trascendentes, los tres primeros -la firma del Acuerdo Nacional para la Modernización de la Educación Básica (ANMEB, 1992), la firma del Compromiso Social por la Calidad de la Educación (CSCE, 2002) y la firma de la Alianza para la Calidad de la Educación (ACE, 2008) - estuvieron marcados por una estrecha cooperación entre la organización magisterial y el gobierno federal, en tanto que el cuarto, la reforma educativa de 2013 estuvo marcada por el acuerdo entre el gobierno federal y los principales partidos políticos.

El Acuerdo Nacional para la Modernización de la Educación Básica (ANMEB) se compuso de tres estrategias: la reorganización del sistema educativo, la reformulación de contenidos y materiales educativos y la revaloración social de la función magisterial. Las estrategias contenidas en este Acuerdo fungieron como una política de Estado sobre la formación docente y calidad educativa del país durante dos períodos presidenciales

\footnotetext{
${ }^{5}$ Basado en su relevancia y peso político, en 2006 el SNTE formó su propio partido político: Nueva Alianza.
} 
primordialmente (Carlos Salinas de Gortari 1988-1944; Ernesto Zedillo 1994-2000).

En conjunto, si bien el ANMEB se convirtió “[...] en una norma cada vez menos adecuada para una sociedad plural, abierta a la globalización y la economía del conocimiento y la creatividad." (TREJO, 2015, p. 132), no se puede dejar de reconocer los elementos disruptivos de la misma, como : i) la descentralización de la educación básica y normal; ii) la introducción del programa de Carrera Magisterial, que fungió como un medio más estructurado de incentivos económicos para el magisterio y la posibilidad de evaluar el hacer del mismo, y iii) la formulación de un primer plan con miras a fortalecer los procesos pedagógicos y de gestión de las escuelas normales del país.

El Compromiso Social por la Calidad de la Educación (CSCE) fue un acuerdo firmado en 2002 entre las autoridades federales, estatales y magisteriales que dio lugar a las siguientes acciones: i) el programa nacional de profesionalización del magisterio, la creación del Instituto Nacional de Evaluación de la Educación y el Sistema Nacional de Evaluación Educativa, la instalación del Consejo Nacional de Participación Social en la Educación, así como la reforma de la educación normal y la creación de la Dirección General de Educación Superior para Profesionales de la Educación.

El acuerdo denominado Alianza para la Calidad de la Educación (ACE) fue suscrito en 2008 en el marco de un convenio entre la Secretaría de Educación Pública y el Sindicato Nacional de Trabajadores de la Educación; así como sus antecesores, éste refrendó acciones en beneficio de la calidad de la educación a través de cinco ejes y 10 líneas de acción. En el segundo eje del ACE "Profesionalización de los maestros y de las autoridades educativas", se decretó la creación del Sistema Nacional de Formación Continua y Superación Profesional de Maestros en Servicio.

En relación al ingreso y promoción, y en continuidad con el CSCE, la ACE planteó al concurso de oposición para la selección, es decir ingreso, de profesores, sin embargo, no fue hasta 2013 -en el marco de la reforma de 
2013- cuando esta intención se acuerpó por un marco normativo legal, previo a ello no se habían establecido reglas formales claras (ESPINOZA, 2012). La ACE incluyó acciones como la creación del Programa de Mejoramiento Institucional de las escuelas normales públicas (PROMIN) y los Centros Regionales de Formación Docente e Investigación Educativa. El SNTE asumió un papel de "corresponsabilidad explícita con la SEP, aunque no necesariamente armónica." (TREJO, 2015, p. 84). Esta disonancia impidió legislar e institucionalizar la ACE; su excesiva carga política, se tradujo en una ruptura de facto entre el SNTE y el Gobierno de Felipe Calderón (2006-2012) con quien se había concertado.

De manera que el proyecto gestado durante veinte años por el SNTE con cuatro gobiernos de distinto signo político, una vez concluido como una Reforma Integral de la Educación Básica y un nuevo currículo que pretendía articular los aspectos fundamentales del proceso educativo, no sobrevivió al primer año del siguiente gobierno. De la misma forma que la reforma educativa de Peña Nieto (2012-2018) tampoco sobrevivió más allá del 2019.

\section{CONCLUSIONES PRELIMINARES}

Con base en el desarrollo de los datos expuestos, se observó que la orientación a lo público, es decir, el grado de articulación de las organizaciones de profesores con las instituciones estatales, es mayor en el caso de México. En el periodo de análisis el SNTE tuvo una estrecha relación con los gobiernos federales en los procesos de reforma; no obstante, en la administración 2013-2018, hubo un abrupto distanciamiento, pasando de relaciones de negociación a la imposición y desvalorización del magisterio.

En el caso de Brasil, el magisterio buscó incidir en la política de Estado a través de la creación en 1980 del PT que -junto a las organizaciones docentes- tuvo por objetivo primordial defender los 
derechos y conquistas laborales, al igual que en Argentina donde la CTERA pasó de ser opositor para convertirse en aliada del Gobierno Federal a partir del triunfo del Partido Justicialista con los Kirchner. Por su parte, en Chile las contradicciones de un modelo impuesto han abierto un diálogo social que rebasa al magisterio, aunque lo incluye, pero que se libra en las calles, en los medios, en las universidades, en el congreso, en fin, en la arena pública, y, desde luego, rebasa el ámbito estrictamente educativo.

Sobre las estrategias de acuerdo entre organizaciones de profesores y autoridades educativas, podemos observar que, a partir de los periodos posteriores a las dictaduras, todas las organizaciones de profesores analizadas tendieron -en diverso grado y forma- a la negociación. De hecho, en todos los casos analizados pudo observarse una disminución en el número de conflictos entre 1998 a 2007. Asimismo, los gremios han aumentado en su organización, por vía de la adscripción a sindicatos, que en todos los casos han privilegiado la agenda laboral; no obstante, los temas por la calidad de la educación han sido también importantes.

Frente a los procesos de reforma educativa, las organizaciones de México y Brasil han demostrado una actitud proactiva en torno al tema, priorizando el fortalecimiento de la educación pública y la profesionalización docente. Por su parte, las organizaciones de profesores de Argentina y Chile privilegiaron la defensa de los derechos laborales.

De acuerdo al análisis de las retóricas educativas, la identidad magisterial y de sus organizaciones gremiales, está comprometida con la "retórica del nacionalismo educativo" que busca hacer de la escuela un elemento al servicio de la formación, consolidación y proyección de la nación, lo cual es una narrativa común a las organizaciones de profesores analizadas y la que determina en gran medida sus posicionamientos políticos.

Finalmente, durante el periodo analizado, las organizaciones i) mantuvieron como norte irrenunciable los valores del nacionalismo educativo: unidad, identidad, solidaridad y la responsabilidad del Estado como proveedor de la educación pública; ii) participaron en decisiones de 
política educativa desde una perspectiva de responsabilidad pública que implicó racionalidades técnicas, políticas y económicas distintas o incluso contrarias a los valores y fines del nacionalismo educativo; iii) participaron del desgaste que necesariamente tuvieron los gobiernos, partidos y líderes con los que se aliaron; iii) perdieron la unidad de visiones, retóricas y objetivos ante la pluralidad de narrativas y alternativas para asumir y atender los desafíos educativos, y iv) en esa fragmentación gremial y dispersión de posicionamientos frente a lo político, comenzó a prevalecer una racionalidad educativa en sentido amplio (ética, pedagógica, socioeducativa) que perfiló ya un modo de ser distinto de la profesión docente, de su profesionalidad y de sus formas de organización y participación en la sociedad.

\section{REFERENCIAS}

AGUILAR, Luis. 1. ed. Gobernanza y Gestión Pública. Ciudad de México: Fondo de Cultura Económica, 2006.

ANDERSON, Benedict. Comunidades imaginadas. Reflexiones sobre el origen y difusión del nacionalismo. México: Fondo de Cultura Económica. 1993.

ARNOLD, Marcelo; OSORIO, Francisco. Introducción a los Conceptos Básicos de la Teoría General de Sistemas. Cinta de Moebio, Valparaiso, n. 3, p. 1-12, abr., 1998. Disponible en: https://www.moebio.uchile.cl/03/frprinci.html. Acceso en: 1.04.2020.

BERTALANFFY, Ludwig Von. 1. ed. Teoría general de los sistemas. Fundamentos, desarrollo, aplicaciones. Ciudad de México: Fondo de Cultura Económica, 1989.

BISCARRA, Constanza; GIACONI, Carolina; ASSAÉL, Jenny. El docente en la legislación educacional chilena. Psicoperspectivas individuo y sociedad, Valparaiso, año 14, n. 3, p. 80-92, oct. 2015. Disponible en: https://scielo.conicyt.cl/scielo.php?script=sci_arttext\&pid=S0718-692420150 00300008. Acceso en: 22.08.2019.

BLANCO, Rosa. Inclusión educativa en américa latina: caminos recorridos y por recorrer. En MARCHESI, Álvaro; BLANCO, Rosa; HERNÁNDEZ, Laura, 
Avances y desafíos de la educación inclusiva en Iberoamérica. Madrid: Organización de Estados Iberoamericanos, 2014, p. 11-36.

CONCHA, Carlos. Gestión de las reformas educacionales en América latina en los 90. Primeras aproximaciones a un proceso complejo. REICE. Revista Iberoamericana sobre Calidad, Eficacia y Cambio en Educación, Madrid, año 3, n. 2, p. 131-153, 2005. Disponible en: http://www.redalyc.org/pdf/551/55103209.pdf. Acceso en: 20.08.2019.

ESPINOZA, Víctor. Una reflexión en torno a la Alianza por la Calidad de la Educación. Revista Mexicana de Orientación Educativa, Ciudad de México, año 9, n. 22, p. 19-31, ene. /jun. 2012. Disponible en: http://pepsic.bvsalud.org/scielo.php?script=sci_arttext\&pid=\$1665-75272012 000100004 . Acceso en: 21.08.2019.

GENTILI, Pablo, et al. Reforma educativa y luchas docentes en América Latina. Revista. Educación Social, Campinas, año. 25, n. 89, p. 1251-1274, sept. $\quad$ /dic. 2004. Disponible en: http://www.scielo.br/pdf/es/v25n89/22620.pdf. Acceso en: 04.04.2020

GINDIN, Julián. Sindicalismo docente en México, Brasil y Argentina. Una hipótesis explicativa de su estructuración diferenciada. Revista Mexicana de Investigación Educativa, Ciudad de México, año 13, n. 37, p. 351-375, abr. jun. 2008.2 Disponible en: http://www.scielo.org.mx/pdf/rmie/v13n37/v13n37a3.pdf. Acceso en: 22.08.2019.

GIROUX, Henry. 2. ed. Los profesores como intelectuales. Hacia una pedagogía crítica del aprendizaje. Barcelona: Centro de Publicaciones del M.E.C. y Paidós, $1997 . \quad$ Disponible en: http://www.terras.edu.ar/biblioteca/11/11DID_Giroux_Unidad_3.pdf. Acceso en: 04.04.2020.

GUTIÉRREZ, Gonzalo. Transformaciones sindicales y pedagógicas en la década del cincuenta: del ocaso de la AMPC a la emergencia de UEPC. Córdova: Centro de Estudios Avanzados, 2014. Disponible en http://biblioteca.clacso.edu.ar/Argentina/cea-unc/20161117032701/pdf_1214.p df. Acceso en: 25.08.2019

HERNÁNDEZ, María; MELLADO, María; MUÑOZ, Omayra. Informe de la Comisión Nacional para la Modernización de la Educación. Temuco: Universidad Católica de Temuco, 2015. Disponible en: https://mariafernandapebm2015.files.wordpress.com/2015/06/tabla-segc3b an-informe-de-brunner-marc3adafernanda1.pdf. Acceso en: 23.08.2019.

JIMÉNEZ, Edgar. Gobernabilidad democrática. En JIMÉNEZ, Edgar, Gobernabilidad y gestión educativa. Ciudad de México: Secretaría de Educación Pública, Subsecretaría de Educación Básica, 2007, p. 83-108. 
LOYO, Aurora. ¿Qué queda hoy de la gran ola de reformas educativas de los años noventa en América Latina? Gaceta año. 4, n. 12, p. 42-48, 2018.

LOYO, Aurora. Los sindicatos docentes en América Latina: entre la lógica laboral y la lógica profesional. Revista Iberoamericana de Educación, Madrid, año 24, n. 25, p. 65-81, ene. /abr. 2001. Disponible en: https://rieoei.org/historico/documentos/rie25a03.htm. Acceso en 19.08.2014.

MENDEZ, José. La política pública como variable dependiente: hacia un análisis integral de las políticas públicas. Foro internacional, Ciudad de México, año 33, n. 1, p. 111-144, ene. / mar. 1993. Disponible en https://forointernacional.colmex.mx/index.php/fi/article/view/1329/1319. Acceso en 01.09.2014.

OLIVEIRA, Heloisa. La construcción de la profesionalidad docente. Educación, año 22, n. 42, p. 97-115, 2013. Disponible en: https://dialnet.unirioja.es/servlet/articulo?codigo=5056907. Acceso en 19.08.2019.

PARSONS, Wayne. Políticas Públicas. Una introducción a la teoría y la práctica del análisis de políticas públicas. 1. ed. Ciudad de México: Facultad Latinoamericana de Ciencias Sociales, 2007.

PERAZZA, Roxana; LEGARRALDE, Martín. Los Sindicatos Docentes en América Latina: Argentina. Santiago de Chile: Centro de Estudios en Políticas Públicas, Fundación Konrad Adenauer Stiftung, 2008.

PROGRAMA DE PROMOCIÓN DE LA REFORMA EDUCATIVA DE AMÉRICA LATINA $Y$ EL CARIBE. Construcción de la profesión docente en América Latina: tendencias, temas y debates. 2004. Disponible en https://www.thedialogue.org/wp-content/uploads/2016/06/2005-Res\%C3\% BAmenes-de-estudios-de-caso-sobre-la-profesionalizaci\%C3\%B3n-docente -en-Am\%C3\%A9rica-Latina.pdf. Acceso en 04.04.2020.

RATINOFF, Luis. La crisis de la educación: el papel de las retóricas y el papel de las reformas. Revista Latinoamericana de Estudios Educativos, Ciudad de México, año 24, n. 3 y 4, p. 505-527, jul. /dic. 1994. Disponible en: https://www.cee.edu.mx/rlee/revista/r1991_2000/r_texto/t_1994_3-4_02.pdf.

Acceso en: 22.08.2019.

SARTORI, Giovanni. La política, lógica y método en las ciencias sociales. Ciudad de México: Fondo de Cultura Económico, 1984.

TEDESCO, Juan. Gobierno y dirección de los sistemas educativos en América Latina. Revista Pensamiento Educativo, Santiago, año 40, n. 1, p. 87-102, $2007 . \quad$ Disponible en: https://pensamientoeducativo.uc.cl/index.php/pel/article/view/400/832. Acceso en: 21.08.2019. 
TEDESCO, Juan; TENTI, Emilio. Nuevos tiempos y nuevos docentes. Buenos Aires: Sede Regional del Instituto Internacional de Planeamiento de la Educación, 2002.

TONON, Graciela. La utilización del método comparativo en estudios cualitativos en ciencia política y ciencias sociales: diseño y desarrollo de una tesis doctoral. KAIROS Revista de Temas Sociales, San Luis, año 15, n. 27, p. 1-12, 2011. Disponible en: https://dialnet.unirioja.es/servlet/articulo?codigo=3702607. Acceso en: 03.04.2020.

TREJO, José. Políticas para la Profesionalización de Magisterio en Contextos de Transición Democrática: Argentina, Brasil, Chile y México. Tuxtla Gutiérrez: Secretaría de Educación del Estado de Chiapas, 2015.

VÁZQUEZ, Gabriela. La calidad de la educación. Reformas educativas y control social en América Latina. Latinoamérica. Revista de Estudios Latinoamericanos, Ciudad de México, n. 60, p. 93-124, ene/jun 2015. Disponible en: http://www.redalyc.org/pdf/640/64039200004.pdf. Acceso en: 22.08.2019.

VEGAS, Eliana; PETROW, Jenny. Incrementar el aprendizaje estudiantil en América Latina. El desafío para el Siglo XXI. Washington, D.C.: Banco Mundial, 2008.

VIEIRA, Márcia. Importancia y significados de la cualificación docente para una central de trabajadores de la educación. El caso de la CTERA (Argentina). Revista mexicana de investigación educativa, Ciudad de México, año 12, n. 37, p. 505-527, abr/jun 2008. Disponible en: http://www.scielo.org.mx/pdf/rmie/v13n37/v13n37a10.pdf. Acceso en: 22.08.2019.

ZAMORA, Carla. Movimientos sociales, democracia y Estado de derecho. Una mirada a la contribución de los movimientos sociales a la democratización e institucionalización del Estado de derecho. Tla-melaua, Puebla, año 9, no. 39, p. 153-171, oct. /mar. 2016. Disponible en http://www.scielo.org.mx/pdf/tla/v9n39/1870-6916-tla-9-39-00152.pdf. Acceso en: 04.04.2020.

\subsection{LEGISLACIÓN CONSULTADA}

ACE (Alianza por la calidad de la educación). Ciudad de México: Diario Oficial de la Federación, 2008. Disponible en: http://www.alianzacivica.org.mx/guia_transparencia/Files/pdf/educacion/9_ ALIANZAPORLACALIDADDELAEDUCACION/9_ALIANZAPORLACALIDADDE LAEDUCACION.pdf. Acceso en: 24.08.2019.

ANMEB (Acuerdo Nacional para la Modernización de la Educación Básica). Ciudad de México: Diario Oficial de la Federación, 19 may. 1992. Disponible 
en

https://www.sep.gob.mx/work/models/sepl/Resource/b490561c-5c33-4254ad1c-aad33765928a/07104.pdf. Acceso en: 22.08.2019.

BRASIL. Presidência da República Casa Civil. Subchefia para Assuntos Jurídicos. Lei $N^{\circ}$ 9394, de 20 de dezembro de 1996. Disponivel em http://www.sipi.siteal.iipe.unesco.org/sites/default/files/sipi_normativa/brasil _ley_nro_9394_1996.pdf. Acesso em 18.05.2020.

CSCE (Compromiso Social por la Calidad de la Educación). Ciudad de México: Diario Oficial de la Federación, 8 ags. 2002. Disponible en http://transparencia.yucatan.gob.mx/datos/2008/sep/marco_Juridico/Com pr_Soc_Cal_Educ.pdf. Acceso en: 23.08.2019.

ESTATUTO DEL DOCENTE ARGENTINO DEL GENERAL PERÓN. Buenos Aires: Poder Ejecutivo Nacional Ministerio de Educación, 14 sep. 1954. Disponible en http://www.bnm.me.gov.ar/gigal/documentos/EL003000.pdf. Acceso en: 20.05.2020. 